\title{
Fertilização silicatada na severidade de brusone e na incidência de insetos-praga em arroz irrigado
}

\author{
Alberto B. dos Santos ${ }^{1}$, Anne S. Prabhu ${ }^{1}$, Evane Ferreira ${ }^{1} \&$ Nand K. Fageria ${ }^{1}$
}

\begin{abstract}
RESUMO
A ocorrência de brusone e insetos-praga tem limitado a produtividade de arroz irrigado na região tropical, razão que este trabalho foi conduzido com o objetivo de avaliar os efeitos do serpentinito calcinado e da volastonita na severidade de brusone, na incidência de insetos-praga e na produtividade de arroz no cultivo principal e na soca. Em casa-de-vegetação foram avaliados os efeitos das doses $0,1,2$, 4 e $8 \mathrm{Mg} \mathrm{ha}^{-1}$ de serpentinito calcinado e volastonita na severidade de brusone nas folhas da cv. Metica 1. No campo, se conduziram dois experimentos em várzeas no município de Dueré, TO, e dois no Formoso do Araguaia, TO. Os tratamentos consistiram das doses 0, 2, 4, 6, $8 \mathrm{Mg} \mathrm{ha}^{-1}$ de serpentinito, com e sem aplicação de produtos fitossanitários e dos genótipos CNA 8502 e BRS Formoso. O serpentinito calcinado foi tão ou mais eficiente que a volastonita na redução da severidade de brusone e aumentou a fitomassa, a produtividade de arroz e a porcentagem de endosperma sem manchas causadas por picadas de percevejo-dos-grãos. A aplicação de Si contribui para o manejo sustentável de brusone e de insetos-praga pela redução das doses de defensivos agrícolas e por um número menor de aplicações foliares, além de melhorar a qualidade do arroz.
\end{abstract}

Palavras-chave: Oryza sativa, Pyricularia grisea, Oebalus spp., serpentinito, volastonita

\section{Silicon fertilization on rice blast severity, insect pest incidence, and grain yield of irrigated rice}

\begin{abstract}
Rice blast and insect pests have laid a ceiling on the grain yield of irrigated rice in tropical regions. The objective of this investigation was to evaluate the effects of calcinated serpentinite and wallastonite on rice blast severity and insect pest incidence as well as grain yield of rice, in the main and ratoon crops. The effect of calcinated serpentinite and wollastonite rates $\left(0,1,2,4\right.$ and $\left.8 \mathrm{Mg} \mathrm{ha}^{-1}\right)$ on leaf blast severity were assessed on cultivar Metica 1, under greenhouse conditions. Two field experiments were conducted in the municipality of Dueré, and two in Formoso do Araguaia, in the State of Tocantins. The treatments consisted of five doses of calcinated serpentinite $\left(0,2,4,6,8 \mathrm{Mg} \mathrm{ha}^{-1}\right)$ with and without fungicide application, and two genotypes BRS Formoso CNA 8502, susceptible and resistant to rice blast, respectively. The calcinated serpentinte was as much as, or more efficient than, wollastonite in reducing blast severity. It increased biomass, grain yield and percentage of endosperms without lesions caused by the rice stink bug. The application of Si contributed to sustainable management of blast and insect pest by reducing the number and doses of chemical foliar sprays, besides increasing the rice quality.
\end{abstract}

Key words: Oryza sativa, rice blast, Pyricularia grisea, Oebalus spp., serpentinite, wollastonite

Embrapa Arroz e Feijão, CP 179, CEP 75375-000, Santo Antônio de Goiás, GO. Fone: (62) 3533-2153. E-mail: baeta@cnpaf.embrapa.br; prabhu@cnpaf.embrapa.br; fageria@cnpaf.embrapa.br 


\section{INTRODUÇÃO}

No Brasil, a maior parcela da produção de arroz provém do cultivo irrigado no ecossistema várzeas, que responde por 69\% da produção (Guimarães et al., 2006). Tem-se verificado na região tropical, que a produtividade de arroz irrigado é menor que a na região subtropical devido à maior influência de fatores bióticos e abióticos sobre a cultura (Santos, 2004). Como fatores bióticos se consideram a ocorrência de doenças, como brusone (Pyricularia grisea), a queima-dabainha (Rhizoctonia solani), a escaldadura (Microdochium oryzae (Hashioka \& Yokogi) Samuels \& I. C.), a manchaparda (Bipolaris oryzae (Breda de Haan) Shoemaker), a mancha-de-grãos (Bipolaris oryzae, Alternaria padwickii, Phoma sorghina, Curvularia lunta), e de insetos-praga, como percevejo-dos-grãos (Oebalus spp. (Dallas) (Santos, 2004). Para minimizar os efeitos desses fatores são requeridas até três aplicações de produtos fitossanitários, o que causa impacto negativo no ambiente. O dano na produtividade causado pelas doenças é variável e depende do sistema de produção, do grau de suscetibilidade da cultivar e das condições climáticas. A durabilidade das cultivares resistentes à brusone é limitada em virtude de plantios contínuos em áreas extensas da mesma cultivar (Prabhu \& Santos, 2004).

O silício ( $\mathrm{Si}$ ) é um elemento benéfico para as plantas (Marschner, 1995), podendo aumentar a produtividade de algumas espécies e potencializar processos fisiológicos nas plantas (Datnoff et al., 2001; Korndörfer et al., 1999b); desta forma, uma das alternativas para o controle de enfermidades consiste no uso de adubação silicatada. O Si promove o crescimento da planta de arroz e eleva o nível de resistência a diferentes enfermidades; é absorvido pelas plantas na forma de ácido monossilícico $\left(\mathrm{H}_{4} \mathrm{SiO}_{4}\right)$ juntamente com a água, fluxo de massa, e se acumula principalmente nas áreas de máxima transpiração, como ácido silícico polimerizado, sílica amorfa. Em geral, são consideradas plantas acumuladoras de Si aquelas que possuem teor foliar acima de $1 \%$ e não acumuladoras plantas com teor de Si menor que 0,5\% (Ma et al., 2001). As plantas de arroz são consideradas acumuladoras e podem conter até $10 \%$ de Si na massa da matéria seca da casca (Kabata-Pendias \& Pendias, 1992).

O Si é o segundo elemento em abundância na crosta terrestre, depois do oxigênio, mas o cultivo intensivo pode reduzir os níveis de Si disponíveis para a planta a ponto de que a suplementação de Si seja necessária. Segundo Korndörfer et al. (1999b), os valores de Si no solo, extraídos com ácido acético $0,5 \mathrm{~mol} \mathrm{~L}^{-1}$, inferiores a $20 \mathrm{mg} \mathrm{dm}^{-3}$ ou, ainda, de 6 a $8 \mathrm{mg} \mathrm{dm}^{-3}$, extraídos em $\mathrm{CaCl}_{2}$ 0,05 mol L-1 indicam, em geral, a necessidade de adubação com Si. O esgotamento do Si no solo é um fator importante e, possivelmente, esteja associado ao decréscimo na produtividade de grãos, em especial nos países tropicais (Savant et al., 1997). No solo, o silício solúvel ou disponível para as plantas pode ter origem nos processos de intemperização dos minerais primários e particularmente dos minerais secundários, como os argilo-silicatos. Os silicatos são as principais fontes de Si para a agricultura e possuem efeito corretivo, mas para que sejam empregados é necessária a retirada dos metais pesados.
Com sua aplicação no solo, o pH e a saturação por bases aumentam e os teores de $\mathrm{Al}^{+3}$ e a saturação por Al diminuem (Korndörfer et al., 1999a).

Adubações nitrogenadas em excesso podem reduzir o teor de Si nas plantas e o número de células epidérmicas silicatadas devido ao efeito de diluição propiciado pelo maior crescimento das plantas. A acumulação de $\mathrm{SiO}_{2}$ nas células da epiderme foliar aumenta a resistência mecânica dos tecidos à incidência de brusone e ao ataque de insetos-praga (Marschner, 1995). A silicificação de células está relacionada com a nutrição de potássio. A deficiência de $\mathrm{K}$ reduz a acumulação de $\mathrm{SiO}_{2}$ nas células da epiderme foliar e facilita a penetração do fungo; enfim, no controle das doenças, o balanço nutricional é tão significativo quanto o nível de um nutriente (Fageria et al., 1997).

Pela análise de 23 experimentos, no período de 1992-1996, Datnoff et al. (2001) observaram um aumento médio da produtividade de arroz de $1.007 \mathrm{~kg} \mathrm{ha}^{-1}$ nas parcelas que receberam Si na forma de silicato de Ca e Mg. Para a obtenção de 75 a $95 \%$ da produção relativa, os autores consideraram os teores médios de Si no solo na faixa de 6,5 a $24,0 \mathrm{mg} \mathrm{dm}^{-3}$ e na palha entre 17 e $34 \mathrm{~g} \mathrm{~kg}^{-1}$. As baixas produtividades foram associadas com os baixos teores de Si na palha do arroz.

No Brasil, existem diversos subprodutos das indústrias de mineração de ferro e fósforo com alto conteúdo de Si sem aproveitamento. A busca de fontes de Si disponíveis mais eficientes no controle de doenças de arroz é iminente.

Objetivou-se, neste trabalho, avaliar os efeitos do serpentinito calcinado e da volastonita na redução da severidade de brusone e da incidência de insetos-praga e na produtividade de arroz no cultivo principal e na soca.

\section{MATERIAL E MÉTODOS}

O estudo consistiu da condução de um experimento em casa-de-vegetação e dois em campo. Em casa-de-vegetação, foi avaliado o efeito das doses de 0, 1, 2, 4 e $8 \mathrm{Mg} \mathrm{ha}^{-1}$ de serpentinito calcinado e volastonita sobre a severidade da brusone nas folhas da cv. Metica 1 de arroz irrigado. A volastonita é um metassilicato de cálcio natural, importado e comercializado como Vansil-EW20, além de considerada uma fonte padrão nos estudos com Si, enquanto o serpentinito calcinado constitui um subproduto da atividade industrial da mineração de amianto, no município de Minaçu, GO, com alto teor de Si e disponível em grande quantidade. A calcinação do produto foi efetuada em mufla, a temperatura de $1.200^{\circ} \mathrm{C}$ e atmosfera normal. O serpentinito e a volastonita apresentaram a seguinte composição química, em porcentagem, respectivamente: $\mathrm{SiO}_{2}=45,5$ e 51,9; $\mathrm{CaO}=0,28$ e 42,1; $\mathrm{Al}_{2} \mathrm{O}_{3}=0,35$ e 1,$82 ; \mathrm{MgO}=18,56$ e 1,$49 ; \mathrm{Fe}_{2} \mathrm{O}_{3}=4,85$ e 0,$34 ; \mathrm{MnO}=0,89$ e 0,03. O delineamento experimental usado foi o de blocos ao acaso, com quatro repetições. Aos 21 dias de idade das plantas nas bandejas $(10 \times 15 \times 30 \mathrm{~cm})$ contendo três quilogramas de solo fertilizado com $5 \mathrm{~g}$ de 5 30-15+Zn e 3 g de sulfato de amônio, efetuaram-se inoculações com suspensão de esporos contendo $3 \times 10^{5}$ conídios/ $\mathrm{mL}$ de isolado virulento de $P$. grisea. Avaliaram-se, também, 
a severidade da brusone nas folhas e a massa da matéria seca da parte aérea (MSPA).

Os experimentos de campo foram conduzidos em dois locais; no primeiro, foram dois experimentos na Fazenda Cachoeirinha, no município de Dueré, TO, e, no segundo, outros dois, no campo experimental da Embrapa Arroz e Feijão, em Formoso do Araguaia, TO, ambos em um Gleissolo Háplico Ta distrófico, textura franco argilo arenosa. Em cada local, em um experimento se usou a cV. BRS Formoso de arroz irrigado susceptível a brusone e no outro a linhagem resistente CNA 8502, para se estudar os efeitos do Si e da aplicação de fungicida. As análises químicas e granulométricas das amostras do solo coletadas no início do estudo, na camada de 0 a $0,20 \mathrm{~m}$, nos primeiro e segundo locais, revelaram 5,3 e 5,5 de $\mathrm{pH}$ em água (1:2,5); 15,4 e

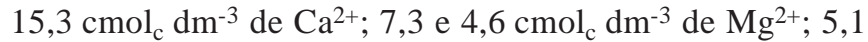
e $26,9 \mathrm{mg} \mathrm{dm}^{-3}$ de $\mathrm{P} ; 70$ e $66 \mathrm{mg} \mathrm{dm}^{-3}$ de $\mathrm{K}^{+}$; 2,6 e $1,9 \mathrm{mg} \mathrm{dm}^{-3}$ de $\mathrm{Cu} ; 2,6$ e 4,0 $\mathrm{mg} \mathrm{dm}^{-3}$ de $\mathrm{Zn} ; 275$ e $78 \mathrm{mg} \mathrm{dm}^{-3}$ de Fe; 10 e $7 \mathrm{mg} \mathrm{dm}^{-3}$ de $\mathrm{Mn} ; 22$ e $30 \mathrm{~g} \mathrm{dm}^{-3}$ de MO; $185 \mathrm{~g} \mathrm{~kg}^{-1}$ de argila; $153 \mathrm{~g} \mathrm{~kg}^{-1}$ de silte; $662 \mathrm{~g} \mathrm{~kg}^{-1}$ de areia, respectivamente.

Avaliaram-se os efeitos das doses de 0, 2, 4, 6, $8 \mathrm{Mg} \mathrm{ha}^{-1}$ de serpentinito calcinado e dos tratamentos fitossanitários sem e com duas pulverizações do fungicida tricyclazole (350 g p.c. ha ${ }^{-1}$ ) e do inseticida lambda - ciolotrina (100 ml p.c. ha-1), aos dez dias antes da emissão das panículas e com cerca de $5 \%$ das panículas emergidas. O serpentinito foi incorporado ao solo com grade niveladora uma semana antes da semeadura. O delineamento experimental foi o de blocos ao acaso, com quatro repetições, no esquema de parcelas divididas constituídas das doses de serpentinito, com $120 \mathrm{~m}^{2}$, e as subparcelas pelos tratamentos fitossanitários, com $60 \mathrm{~m}^{2}$; na semeadura se usou o sistema de linhas espaçadas $0,17 \mathrm{~m}$ com 80 sementes por metro e se aplicaram, no primeiro local, $350 \mathrm{~kg} \mathrm{ha}^{-1}$ do formulado 4-25-25 e $35 \mathrm{~kg} \mathrm{ha}^{-1}$ de $\mathrm{N}$ no perfilhamento e na diferenciação do primórdio floral, na forma de uréia e, na soca, 167 kg ha-1 de 30-00-20, imediatamente após a colheita; já no segundo local foram aplicados $400 \mathrm{~kg} \mathrm{ha}^{-1}$ de 4-30-16 + Zn e a mesma adubação nitrogenada em cobertura.

Aos 35 dias após a emergência (DAE) das plântulas, determinou-se a severidade de brusone nas penúltimas folhas dos colmos principais, usando-se uma escala de dez graus (0; 0,$5 ; 1,0 ; 2,0 ; 4,0 ; 8,0 ; 16,0 ; 32,0 ; 64,0 ; 82,0 \%$ da área foliar infectada) de acordo com Notteghem (1981). Para avaliação do índice de mancha-de-grãos por ocasião da colheita, 20 panículas foram coletadas, trilhadas e retiradas duas amostras de 100 grãos, os quais, por sua vez, foram separados em quatro categorias, de acordo com a severidade de manchas, com base na escala de Araujo \& Prabhu (2002): 0, 1 , 2 e 4, sendo, 0 = ausência de manchas; 1 = pontuações do tamanho da cabeça de um alfinete; 2 = manchas bem definidas com aproximadamente $25 \%$ de área manchada e 4 $=50 \%$ ou mais de área coberta com manchas. A incidência de mancha-de-grãos foi determinada pela fórmula índice de mancha-de-grãos = S (valor de classe $\mathrm{x}$ freqüência) /número total de grãos.

Realizaram-se, durante o ciclo das plantas de arroz, avali- ações na infestação e dano de insetos que atacaram folhas, colmos, raízes e panículas. As amostragens dos artrópodes foram realizadas com rede de varredura, efetuando-se três redadas simples por subparcela e, para a determinação do dano de lagarta foram examinadas as três últimas folhas e, para o ataque de gorgulho aquático, postura de Diatraea e coraçãomorto por Diatraea e Tibraca, avaliaram-se dez colmos em cada subparcela. A qualidade de grãos foi avaliada em 50 espiguetas, pela emergência de plântulas e manchas no endosperma causadas por picadas de percevejo-dos-grãos.

Realizaram-se, por ocasião da colheita, amostragens de plantas, as quais foram separadas em folhas e colmos + bainhas das quais, após secadas, se determinou a MSPalha e MSPA. A produtividade de grãos foi ajustada em 13\% de umidade. Para a avaliação da qualidade industrial de grãos as amostras foram secadas até $13 \%$ de umidade e armazenadas 30 dias; logo após, amostras de 100 g de sementes foram beneficiadas utilizando-se engenho de prova da marca Suzuki e, a seguir, determinou-se a massa de grãos inteiros e total, inteiros mais quebrados. Os dados foram submetidos a análise de variância e, quando significativos, a análise de regressão. As médias dos fatores qualitativos foram comparadas pelo teste de Tukey, a 5\% de probabilidade.

\section{RESULTADOS E DISCUSSÃO}

Em casa-de-vegetação a aplicação de serpentinito reduziu a severidade da brusone nas folhas de arroz aos 32 DAE com resposta quadrática, tendo a máxima eficiência com 6,1 $\mathrm{Mg} \mathrm{ha}^{-1}$ (Figura 1A). A volastonita reduziu linearmente a severidade da brusone nas folhas a uma taxa de 3,8\% por tonelada; com esta fonte, Pereira et al. (2004) verificaram aumento linear na disponibilidade de Si no solo e, consequentemente, na sua absorção pela cv. BRS Formoso de arroz irrigado com aumento da dose. Foi quadrática a resposta da MSPA às doses das duas fontes de Si, sendo as máximas MSPA de 2,24 e 1,64 g por 20 plantas obtidas com 3,8 $\mathrm{Mg} \mathrm{ha}^{-1}$ de serpentinito e de volastonita, respectivamente (Figura 1B); isso indica que o efeito do serpentinito no crescimento e desenvolvimento das plantas foi mais expressivo que o da mesma dose de volastonita.

Nos dois locais, em condições de campo os tratamentos influenciaram diferentemente o desempenho dos dois genótipos (Tabela 1). Com a linhagem CNA 8502, não se observou qualquer influência das doses de serpentinito e dos tratamentos fitossanitários sobre as características das plantas do cultivo principal e da soca; entretanto, com a cV. BRS Formoso houve efeitos de doses de serpentinito sobre a MSPA, a produtividade do cultivo principal e a soma das produtividades de grãos do cultivo principal e da soca, e não ocorreu interação com os tratamentos fitossanitários.

No primeiro local, as doses de serpentinito exerceram efeito linear sobre a massa da matéria seca de palha (MS Palha) e quadrático sobre a MSPA do cultivo principal, sendo a biomassa máxima de $1.378 \mathrm{~g} \mathrm{~m}^{-2}$ obtida com a dose de 6,8 $\mathrm{Mg} \mathrm{ha}^{-1}$ (Tabela 2). Lee et al. (1990) também verificaram efeitos da aplicação de silicato, como aumento do número e 

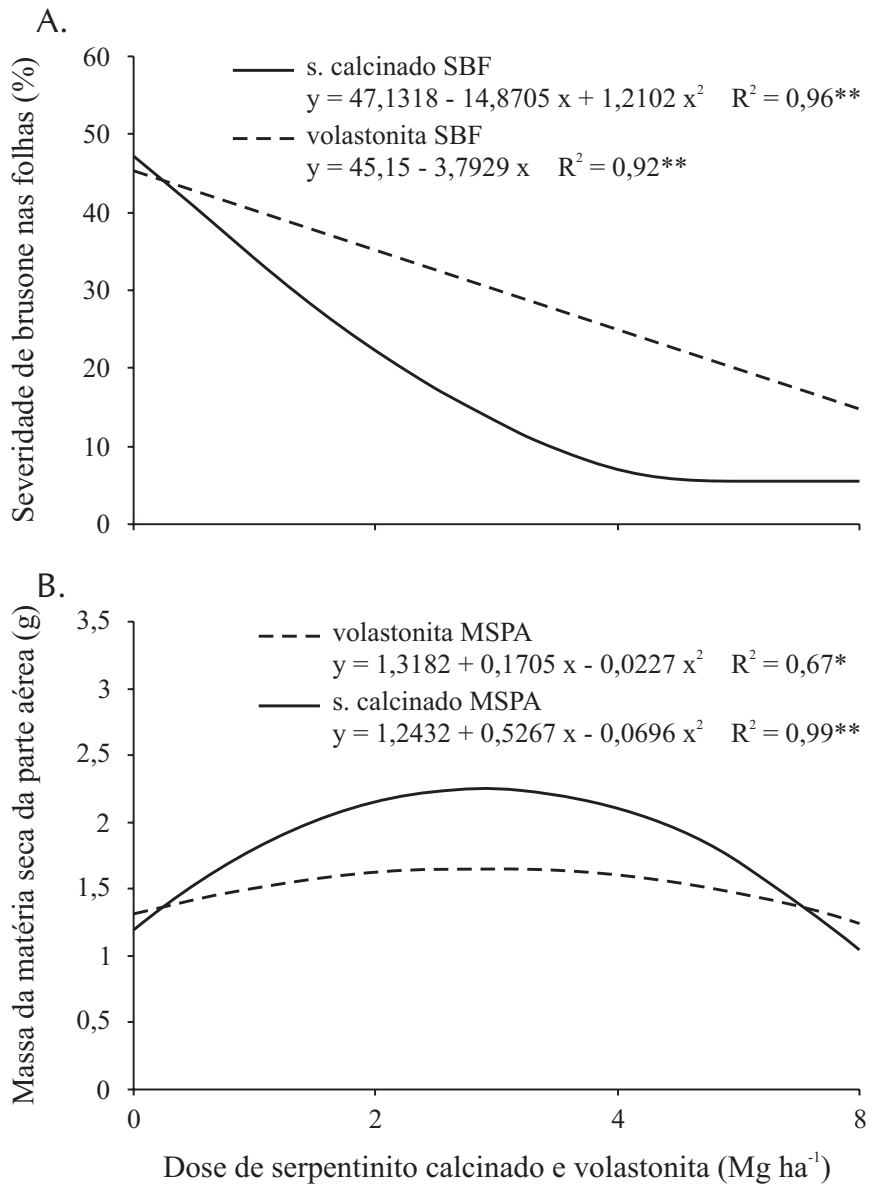

Figura 1. Relação das doses das fontes de Si com a severidade da brusone nas folhas (SBF) (A) e com a massa da matéria seca da parte aérea (MSPA) (B) de 20 plantas da cultivar Metica 1 de arroz irrigado, em casa-devegetação

da matéria seca de folhas, número de espiguetas por panículas e qualidade dos grãos. Segundo os autores, isto se deve ao aumento da taxa fotossintética da planta e da eficiência de uso da água devido à prevenção de perda pela transpiração. A produtividade de grãos do cultivo principal e a soma das produtividades do cultivo principal e da soca aumentaram linearmente com as doses de serpentinito, não sendo possível, portanto, determinar a dose que possibilita a maior resposta das plantas (Tabela 2). O incremento foi de 63 e $68 \mathrm{~kg} \mathrm{ha}^{-1}$ no cultivo principal e na soma dos dois cultivos, respectivamente. A produtividade da soca não foi influenciada pelas doses de serpentinito; assim, esta resposta se deve exclusivamente ao efeito no cultivo principal.

A infestação de artrópodes determinada em amostragens durante o ciclo do cultivo principal e da soca de arroz, diferiu apenas entre os genótipos (Tabela 3). Verificou-se maior número de lagartas, gafanhotos, cicadelídeos, O. poecilus e O. ypsilongriseus por redada na linhagem CNA 8502 que na cv. BRS Formoso, exceto de gafanhotos e cicadelídeos, aos 78 DAE, e de delfacídeos, aos 29 DAE. A cv. BRS Formoso apresentou maiores percentuais de colmos com coração-morto, o que causou menor fertilidade de perfilhos, e de panículas com ataque na folha bandeira que a linhagem CNA 8502 (Tabela 3); apresentou, também, melhor qualidade de grãos, pois teve mais endosperma sem manchas e massa de espiguetas por panícula. Os percentuais de folhas atacadas por mastigadores e de plântulas emergidas não diferiram entre os genótipos. O desempenho da linhagem CNA 8502 pode indicar maior resistência aos insetos-praga que a cv. BRS Formoso. Ferreira (2006) menciona que, em vários estudos, se verificou a existência de variabilidade genética de arroz a determinados insetos-praga, como a Diatraea saccharalis, Tibraca limbativentris e O. poecilus.

Houve interação entre sistema de cultivo, principal e soca, e genótipo na qualidade de grãos (Figura 2). A linhagem CNA 8502 apresentou danos mais severos causados por artrópodes na soca que no cultivo principal e a cv. BRS Formoso nos dois sistemas de cultivo, pois teve menores

Tabela 1. Resumo das análises da variância, expresso em quadrados médios, dos efeitos de doses de serpentinito calcinado, de tratamentos fitossanitários e de suas interações sobre algumas características dos genótipos de arroz irrigado, nos dois locais

\begin{tabular}{|c|c|c|c|c|c|c|c|}
\hline Local & Genótipo & Fonte de variação & $\begin{array}{l}\text { Produtividade de } \\
\text { grãos }\left(\mathrm{kg} \mathrm{ha}^{-1}\right)\end{array}$ & MS Palha' ${ }^{1}\left(\mathrm{~g} \mathrm{~m}^{-2}\right)$ & $\operatorname{MSPA}^{2}\left(\mathrm{~g} \mathrm{~m}^{-2}\right)$ & $\mathrm{RGI}^{3}(\%)$ & RIG $^{4}(\%)$ \\
\hline \multirow{8}{*}{ Dueré } & \multirow{4}{*}{ CNA 8502} & Dose & $351465^{\mathrm{ns}}$ & $32651^{\text {ns }}$ & $74029^{\text {ns }}$ & $4,7558^{\mathrm{ns}}$ & $1,5432^{\mathrm{ns}}$ \\
\hline & & Fito & $72505^{\text {ns }}$ & $156,02^{\text {ns }}$ & $1562,5^{\mathrm{ns}}$ & $8,2810^{\text {ns }}$ & $0,8702^{\text {ns }}$ \\
\hline & & Dose $X$ Fito & $640522^{\text {ns }}$ & $16688,65^{\mathrm{ns}}$ & $82920^{\text {ns }}$ & $1,6737^{\mathrm{ns}}$ & $2,8057^{\mathrm{ns}}$ \\
\hline & & C. V. (\%) & 13,7 & 20,6 & 20,2 & 3,2 & 2,0 \\
\hline & \multirow{4}{*}{ BRS Formoso } & Dose & $870072^{\star \star}$ & $20239 * \star$ & $70275^{\star \star}$ & $14,1417^{\text {ns }}$ & $5,4951^{\text {ns }}$ \\
\hline & & Fito & $65691^{\text {ns }}$ & $2576^{\text {ns }}$ & $21855^{\mathrm{ns}}$ & $3,3350^{\mathrm{ns}}$ & $1,3690^{\mathrm{ns}}$ \\
\hline & & Dose X Fito & $188485^{\text {ns }}$ & $13298^{\text {ns }}$ & $58941^{\text {ns }}$ & $6,2107^{\mathrm{ns}}$ & $1,0808^{\mathrm{ns}}$ \\
\hline & & C. V. $(\%)$ & 5,6 & 14,1 & 13,8 & 4,4 & 1,2 \\
\hline \multirow{8}{*}{$\begin{array}{l}\text { Formoso do } \\
\text { Araguaia }\end{array}$} & \multirow{4}{*}{ CNA 8502} & Dose & $402675^{\text {ns }}$ & $79384^{\text {ns }}$ & $167656^{\text {ns }}$ & $40,8886^{\mathrm{ns}}$ & $1,5555^{\mathrm{ns}}$ \\
\hline & & Fito & $1624896^{\text {ns }}$ & $8196.7^{\text {ns }}$ & $62805^{\mathrm{ns}}$ & $253,562^{\text {ns }}$ & $0,25760^{\text {ns }}$ \\
\hline & & Dose X Fito & $193328^{\mathrm{ns}}$ & $29278.7^{\text {ns }}$ & $152289^{n s}$ & $43,8342^{\mathrm{ns}}$ & $2,7541^{\mathrm{ns}}$ \\
\hline & & C. V. (\%) & 13,2 & 18,1 & 15,4 & 16,7 & 2,0 \\
\hline & \multirow{4}{*}{ BRS Formoso } & Dose & $2334071^{*}$ & $75600^{*}$ & $17033^{\text {ns }}$ & $2,6866^{\mathrm{ns}}$ & $0,6868^{\text {ns }}$ \\
\hline & & Fito & $5597284^{\star *}$ & $183832^{\text {ns }}$ & $462508^{\text {ns }}$ & $12,6562^{\star}$ & $12,210 * *$ \\
\hline & & Dose $X$ Fito & $721091^{\mathrm{ns}}$ & $63442^{\text {ns }}$ & $184011^{\text {ns }}$ & $3,4793^{\text {ns }}$ & $1,7371^{\mathrm{ns}}$ \\
\hline & & C. V. (\%) & 10,2 & 27,8 & 27 & 2,6 & 1,1 \\
\hline
\end{tabular}

\footnotetext{
**, ${ }^{*}$, ns Significativo a 1 e a $5 \%$ de probabilidade e não significativo, respectivamente
}

${ }^{1}$ Massa da matéria seca de palha; ${ }^{2}$ Massa da matéria seca total da parte aérea; ${ }^{3}$ Rendimento de grãos inteiros; ${ }^{4}$ Rendimento industrial de grãos 
Tabela 2. Equações de regressão da massa da matéria seca e da produtividade de grãos da cultivar BRS Formoso de arroz irrigado obtidas em razão da aplicação de doses de serpentinito calcinado e coeficientes de determinação $\left(R^{2}\right)$, nos dois locais

\begin{tabular}{|c|c|c|c|}
\hline Local & Característica & Equação de regressão & $\mathbf{R}^{2}$ \\
\hline \multirow{4}{*}{ Dueré } & MS Palha1 ${ }^{1}\left(\mathrm{~g} \mathrm{~m}^{-2}\right)$ & $y=612,68+14,3125 x$ & $0,57^{* *}$ \\
\hline & $\operatorname{MSPA}^{2}\left(\mathrm{~g} \mathrm{~m}^{-2}\right)$ & $y=1168,19+62,04 x-4,583 x^{2}$ & $0,57^{* *}$ \\
\hline & Produtividade de grãos do $\mathrm{CP}^{3}\left(\mathrm{~kg} \mathrm{ha}^{-1}\right)$ & $y=5194,85+62,52 x$ & $0,81^{* *}$ \\
\hline & Produtividade de grãos $(\mathrm{CP}+$ soca $)\left(\mathrm{kg} \mathrm{ha}^{-1}\right)$ & $y=6556,63+67,66 x$ & 0,69 ** \\
\hline \multirow{3}{*}{ Formoso do Araguaia } & MSPA $\left(\mathrm{g} \mathrm{m}^{-2}\right)$ & $y=719,48+62,401 x-7,387 x^{2}$ & $0,34^{*}$ \\
\hline & Produtividade de grãos do CP (kg ha $\left.{ }^{-1}\right)$ & $y=6179,25+164,69 x$ & $0,93^{* *}$ \\
\hline & Severidade de brusone nas folhas (SBF) (\%) & $y=23,23-1,4833 x$ & $0,95^{\star *}$ \\
\hline
\end{tabular}

** * Significativo a 1 e a $5 \%$ de probabilidade, respectivamente

${ }^{1}$ Massa da matéria seca de Palha; ${ }^{2}$ Massa da matéria seca total da parte aérea; ${ }^{3} \mathrm{CP}$ Cultivo principal

Tabela 3. Infestação de artrópodes determinada em amostragens durante o ciclo do cultivo principal e da soca e dano em genótipos de arroz irrigado

\begin{tabular}{|c|c|c|c|c|c|c|c|c|c|c|}
\hline \multirow{3}{*}{ Genótipo } & \multicolumn{10}{|c|}{ Infestação de artrópodes $\left(\mathrm{n}^{0}\right.$ redada $\left.^{-1}\right)$} \\
\hline & \multicolumn{2}{|c|}{ Lagarta } & \multicolumn{2}{|c|}{ Gafanhoto } & \multicolumn{3}{|c|}{ Cicadelídeo } & \multirow{2}{*}{$\begin{array}{c}\text { Delfacídeo } \\
29 \text { DAE }\end{array}$} & \multirow{2}{*}{$\begin{array}{c}\text { Oebalus } \\
\text { poecilus } \\
55 \text { DAC }\end{array}$} & \multirow{2}{*}{$\begin{array}{c}\text { Oebalus } \\
\text { ypsilongriseus } \\
55 \text { DAC }\end{array}$} \\
\hline & 29 DAE $^{1}$ & 78 DAE & $29 \mathrm{DAE}$ & 78 DAE & 29 DAE & 78 DAE & $55 \mathrm{DAC}^{2}$ & & & \\
\hline BRS Formoso & $1,2 b^{3}$ & $0,5 \mathrm{~b}$ & $1,8 \mathrm{~b}$ & $1,9 \mathrm{a}$ & $0,1 \mathrm{~b}$ & $1,7 \mathrm{a}$ & $0,7 \mathrm{~b}$ & $0,1 \mathrm{a}$ & $1,1 \mathrm{~b}$ & $0,1 \mathrm{~b}$ \\
\hline \multirow[t]{3}{*}{ CNA 8502} & $3,4 \mathrm{a}$ & $5,1 \mathrm{a}$ & $3,6 \mathrm{a}$ & $1,0 \mathrm{~b}$ & $0,3 \mathrm{a}$ & $1,6 \mathrm{a}$ & $1,4 \mathrm{a}$ & $0,1 \mathrm{a}$ & $16,3 \mathrm{a}$ & $2,2 \mathrm{a}$ \\
\hline & \multicolumn{10}{|c|}{ Dano causado por artrópodes (\%) } \\
\hline & \multicolumn{2}{|c|}{ Folhas atacadas } & $\begin{array}{l}\text { Colmos com } \\
\text { coração morto }\end{array}$ & $\begin{array}{l}\text { Perfilhos } \\
\text { férteis }\end{array}$ & \multicolumn{2}{|c|}{$\begin{array}{l}\text { Panículas c/ ataque } \\
\text { na folha bandeira }\end{array}$} & $\begin{array}{l}\text { Plântulas } \\
\text { emergidas }\end{array}$ & $\begin{array}{l}\text { Endosperma } \\
\text { sem manchas }\end{array}$ & \multicolumn{2}{|c|}{$\begin{array}{l}\text { Massa de espiguetas } \\
\text { (g panícula-1) }\end{array}$} \\
\hline BRS Formoso & \multicolumn{2}{|c|}{$5,0 \mathrm{a}$} & $14,0 \mathrm{a}$ & $94,6 \mathrm{~b}$ & \multicolumn{2}{|c|}{$15,8 \mathrm{a}$} & $79,4 \mathrm{a}$ & $91,7 \mathrm{a}$ & \multicolumn{2}{|c|}{$1,58 \mathrm{a}$} \\
\hline CNA 8502 & \multicolumn{2}{|c|}{$2,7 \mathrm{a}$} & $4,0 \mathrm{~b}$ & $97,0 \mathrm{a}$ & \multicolumn{2}{|c|}{$7,8 \mathrm{~b}$} & $79,3 \mathrm{a}$ & $87,7 \mathrm{~b}$ & \multicolumn{2}{|c|}{$1,37 \mathrm{~b}$} \\
\hline
\end{tabular}

${ }^{1}$ Dias após a emergência das plântulas; ${ }^{2}$ Dias após a colheita do cultivo principal; ${ }^{3}$ Médias seguidas da mesma letra não diferem entre si, pelo teste de Tukey $(\mathrm{P}<0,05)$

porcentagens de endosperma sem manchas causadas por picadas de percevejo-dos-grãos e de plântulas emergidas. Ferreira (2004) relata maior número de $O$. poecilus coletado com rede de varredura na soca que no cultivo principal. O autor considera que, em condições tropicais, o Oebalus spp. é, provavelmente uma ameaça fundamental ao cultivo da soca, seja pela reincidência de adultos e ninfas do cultivo principal ou por migração de outras áreas. As doses de serpentinito apresentaram efeito quadrático sobre a porcentagem de endosperma sem manchas, obtendo-se o valor máximo de 91,8\% com a dose de 4,5 $\mathrm{Mg} \mathrm{ha}^{-1}$ (Figura 3A). A emergência de plântulas não foi influenciada pela fertilização silicatada. Ferreira (2006) menciona que áreas escuras na casca e brancas no endosperma são formadas quando o ataque de percevejo-dos-grãos ocorre na fase final de desenvolvimento do grão, o que causa o seu enfraquecimento e, comumente, a quebra, durante o beneficiamento.

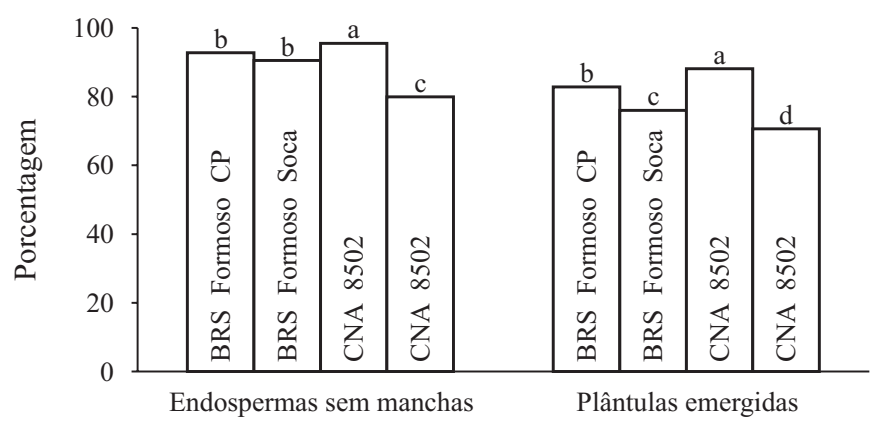

Figura 2. Efeitos da interação entre sistema de cultivo, principal e soca, e genótipo, BRS Formoso e CNA 8502, na qualidade de grãos de arroz avaliada pelas porcentagens de manchas no endosperma causadas por picada de percevejo-dos-grãos e de emergência de plântulas, no primeiro local
Segundo Deren et al. (1994), alguns genótipos de arroz são mais eficientes que outros no acúmulo de Si, o que, possivelmente, contribui para aumentar o nível de resistência das plantas a doenças e insetos. Sawant et al. (1994) demonstraram que alguns insetos-praga de importância econômica, como broca-do-colmo e ácaros, têm sido controlados com aplicação de Si.

Na soca, a aplicação de produtos fitossanitários propiciou maior rendimento de grãos inteiros e menor índice de mancha-de-grãos que a testemunha (Tabela 4). Prabhu \& Santos (2004) consideraram que a mancha-de-grãos, cujo principal patógeno é Bipolaris oryzae, é mais importante na soca que no cultivo principal e sua severidade pode ser reduzida com controle químico.

No segundo local as doses de serpentinito tiveram efeito quadrático sobre a MSPA (Tabela 2), sendo a massa máxima de MSPA de $851 \mathrm{~g} \mathrm{~m}^{-2}$ obtida com a dose de 4,2 $\mathrm{Mg} \mathrm{ha}^{-1}$. Maior crescimento das plantas de arroz pela aplicação de $\mathrm{SiO}_{2}$ também foi observado por Prabhu et al. (2001). A produtividade de grãos aumentou linearmente com o aumento das doses de serpentinito. O incremento foi de $165 \mathrm{~kg}$ de grãos por tonelada de serpentinito aplicada por hectare. Carvalho-Pupatto et al. (2003) verificaram que o uso de escória contendo Si aumentou o crescimento e a superfície radicular, diminuiu o diâmetro das raízes e elevou os teores de Si no solo e na planta, o que resultou em aumento da produtividade de arroz. Em várzea tropical, Santos et al. (2003) verificaram que o Si reduziu a severidade de brusone foliar, não afetou a brusone nas panículas e a mancha-de-grãos e aumentou a produtividade da cv. Javaé com até $4 \mathrm{Mg} \mathrm{ha}^{-1}$ de silicato de cálcio.

A severidade de brusone nas folhas da cV. BRS Formoso 
Tabela 4. Efeitos da aplicação de produtos fitossanitários no rendimento de grãos inteiros e no índice de mancha-de-grãos da soca, no primeiro local, e na severidade de brusone nas panículas, no rendimento de grãos inteiros, no rendimento industrial de grãos e na produtividade de grãos do cultivo principal da cultivar BRS Formoso de arroz irrigado, no segundo local

\begin{tabular}{|c|c|c|c|c|c|c|}
\hline \multirow[b]{2}{*}{ Tratamento } & \multicolumn{3}{|c|}{ Primeiro local soca } & \multicolumn{3}{|c|}{ Segundo local cultivo principal } \\
\hline & $\begin{array}{l}\text { Rendimento de grãos } \\
\text { inteiros (\%) }\end{array}$ & $\begin{array}{l}\text { Índice de mancha- } \\
\text { de-grãos (nota) }\end{array}$ & $\begin{array}{c}\text { Severidade de brusone } \\
\text { na panícula }(\%)\end{array}$ & $\begin{array}{l}\text { Rendimento de grãos } \\
\text { inteiros (\%) }\end{array}$ & $\begin{array}{l}\text { Rendimento industrial } \\
\text { de grãos (\%) }\end{array}$ & $\begin{array}{l}\text { Produtividade de grãos } \\
\qquad\left(\mathrm{kg} \mathrm{ha}^{-1}\right)\end{array}$ \\
\hline Sem pulverização & $53 b^{1}$ & $1,10 \mathrm{a}$ & $4,4 \mathrm{a}$ & $53 \mathrm{~b}$ & $63 \mathrm{~b}$ & $6.464 \mathrm{~b}$ \\
\hline Com pulverização & $55 \mathrm{a}$ & $0,86 \mathrm{~b}$ & $2,5 \mathrm{~b}$ & $55 \mathrm{a}$ & $65 \mathrm{a}$ & $7.212 \mathrm{a}$ \\
\hline
\end{tabular}

${ }^{1}$ Médias seguidas da mesma letra não diferem entre si, pelo teste de Tukey $(\mathrm{P}<0,05)$

declinou linearmente com o aumento da dose de serpentinito (Tabela 2); tal decréscimo correspondeu a uma taxa de $1,48 \%$ na severidade de brusone por tonelada de serpentinito aplicada. Tem-se verificado grande potencial de uso de silicato de cálcio no manejo da brusone (Datnoff et al., 1991; Prabhu et al., 2001; Seebold et al., 2004). Nos estudos de Berni \& Prabhu (2003), a fertilização silicatada aumentou a eficiência do tratamento das sementes na redução da brusone nas folhas. Os autores obtiveram diminuição da severidade da brusone com o aumento das doses de Si e verificaram que as correlações entre a área sob a curva de progresso da doença e as doses foram lineares e negativas. O papel do Si na resistência da brusone tem sido considerado principalmente mecânico, pela formação de uma barreira física à penetração do fungo (Datnoff et al., 2001). Por ocasião da colheita da cv. BRS Formoso, o índice de mancha-de-grãos causada por fungos declinou quadraticamente, obtendo-se o menor valor com 5,2 $\mathrm{Mg} \mathrm{ha}^{-1}$ de serpentinito (Figura 3b). Em vários países, estudos demostraram que as severidades de brusone e de mancha-parda em arroz foram reduzidas com a fertilização silicatada (Kim \& Lee, 1982; Nanda \& Gangopadhya, 1984; Datnoff et al., 1991; Prabhu et al., 2001). Estudos de Datnoff et al. (1991) indicaram que a fertilização com Si na cultura do arroz reduziu a incidência de brusone entre 17 e 31\%. Segundo Korndörfer et al. (1999b), o Si pode aumentar a produtividade não apenas das plantas conhecidas como acumuladoras, como arroz, cana e pastagem, mas também das não-acumuladoras de Si, devido ao aumento da resistência a insetos-praga e doenças, acamamento e estresse hídrico.

No cultivo principal as pulverizações com o fungicida tricyclazole reduziram a severidade de brusone nas panículas, aumentaram a produtividade e o rendimento de grãos inteiros, o que resultou na melhoria da qualidade industrial de grãos da cv. Formoso (Tabela 4). Em experimentos realizados na Colômbia, Seebold et al. (2004) constataram que a aplicação de $1 \mathrm{Mg} \mathrm{ha}^{-1}$ de silício reduziu a brusone nas panículas mais eficientemente ou melhor que a pulverização do fungicida tricyclazole.

O manejo do Si na nutrição de plantas poderá contribuir de forma significativa para uma agricultura mais sustentável e menos poluente. A integração de medidas de controle, como o emprego de cultivares com resistência genética e práticas culturais, nas quais se inclui a fertilização silicatada, permite reduzir as doses dos produtos fitossanitários usados no tratamento de sementes e por um número menor de aplicações, o que reduz o custo de produção e aumenta a quantidade e qualidade comercial da

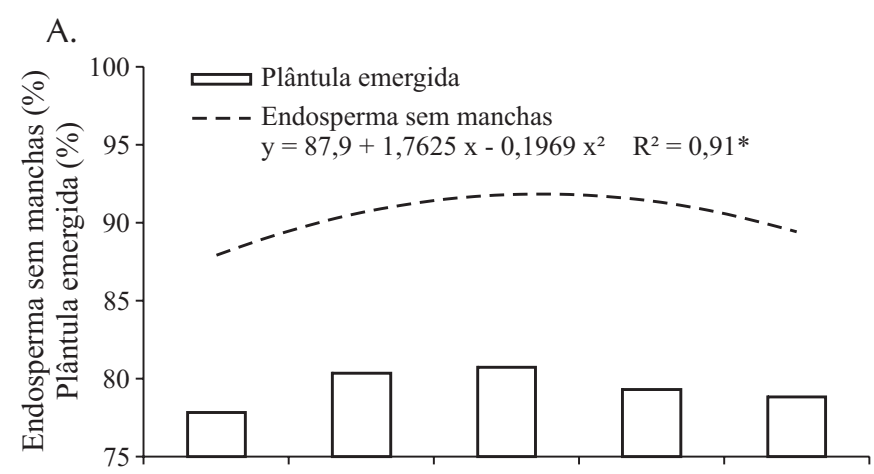

B.

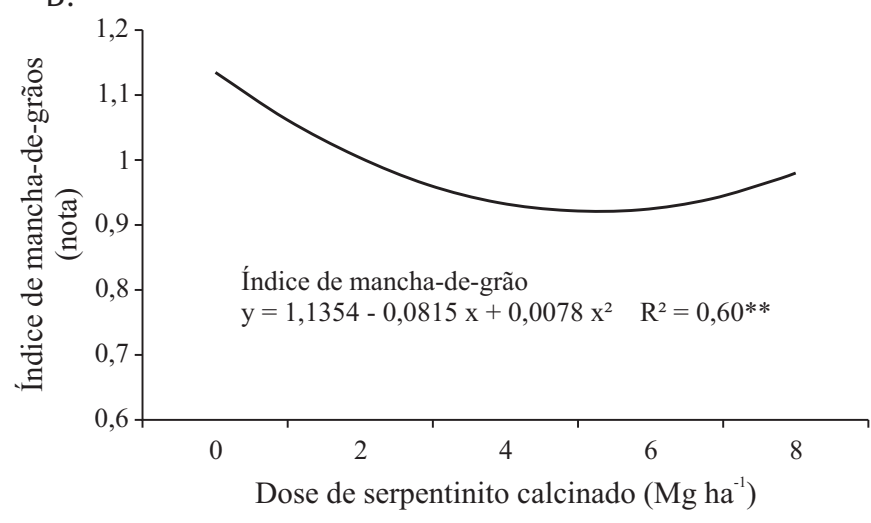

Figura 3. Efeitos do serpentinito calcinado na qualidade de grãos de arroz avaliada pelas porcentagens de manchas no endosperma, causadas por picada de percevejo-dos-grãos (Oebalus spp.), na cultivar BRS Formoso e de plântulas emergidas dos dois genótipos, no primeiro local (A), e no índice de mancha-de-grãos causada por fungos na cultivar BRS Formoso, no segundo local (B)

produção, mediante a redução da população do patógeno em níveis toleráveis.

\section{CONCLUSÕES}

1. O serpentinito calcinado é tão ou mais eficiente que a volastonita na redução da severidade de brusone e no crescimento do arroz irrigado.

2. O serpentinito calcinado aumenta a fitomassa, a qualidade e a produtividade de grãos apenas da cultivar de arroz irrigado susceptível a brusone.

3. A porcentagem de endosperma com manchas causadas por picadas de percevejo-dos-grãos, da cv. BRS Formoso, se reduz com o aumento das doses de serpentinito calcinado.

4. A aplicação de Si contribui para o manejo sustentável 
de brusone e de insetos-praga, melhora a qualidade comercial e aumenta a produtividade de arroz irrigado.

\section{AGRADECIMENTOS}

Dedicamos este trabalho ao inesquecível companheiro Evane Ferreira (In memoriam), pesquisador da Embrapa Arroz e Feijão, pelos inestimáveis serviços prestados ao Brasil, no campo da entomologia agrícola, dedicando-se com tanto entusiasmo à tarefa de contribuir para o estabelecimento do manejo integrado de pragas da cultura do arroz e, em especial, pela participação em todas as etapas desta pesquisa.

\section{LITERATURA CITADA}

Araujo, L. G.; Prabhu, A. S Indução de variabilidade na cultivar de arroz Metica-1 para resistência a Pyricularia grisea. Pesquisa Agropecuária Brasileira, v.37, n.12, p.1689-1695, 2002.

Berni, R. F.; Prabhu, A. S. Eficiência relativa de fontes de silício no controle de brusone nas folhas em arroz. Pesquisa Agropecuária Brasileira, v.38, n.2, p.195-201, 2003.

Carvalho-Pupatto, J. G.; Bull, L. T.; Crusciol, C. A. C.; Mauad, M.; Silva, R. H. da. Efeito de escória de alto forno no crescimento radicular e na produtividade de arroz. Pesquisa Agropecuária Brasileira, v.38, n.11, p.1323-1328, 2003.

Datnoff, L. E.; Raid, R. N.; Snyder, G. H.; Jones, D. B. Effect of calcium silicate slag on blast and brown spot intensities and yield of rice. Plant Disease, v.75, p.729-732, 1991.

Datnoff, L. E., Snyder, G. H., Korndörfer, G. H. Silicon in agriculture. Amsterdam: Elsevier, 2001. 403p.

Deren, C. W.; Datnoff, L. E.; Snyder, G. H.; Martin, F. G. Silicon concentration, disease response and yield components of rice genotypes grown on flooded organic Histosols. Crop Science, v.34, p.733-737, 1994.

Fageria, N. K.; Baligar, V. C.; Jones, C. A. Growth and mineral nutrition of field crops. 2.ed. New York: Marcel Dekker, 1997. 624p.

Ferreira, E. Orizívoros e seu controle. In: Santos, A. B. dos. (ed.). Cultivo da soca de arroz irrigado. Santo Antônio de Goiás: Embrapa Arroz e Feijão, 2004. p.127-172.

Ferreira, E. Fauna prejudicial. In: Santos, A. B. dos; Stone, L. F.; Vieira, N. R. de A. (ed.). A cultura do arroz no Brasil. Santo Antônio de Goiás: Embrapa Arroz e Feijão, 2006. p.539-620.

Guimarães, C. M.; Santos, A. B. dos; Magalhães Júnior, A. de M.; Stone, L. F. Sistemas de cultivo. In: Santos, A. B. dos; Stone, L. F.; Vieira, N. R. de A. (ed.). A cultura do arroz no Brasil. Santo Antônio de Goiás: Embrapa Arroz e Feijão, 2006. p.53-96.

Kabata-Pendias, A.; Pendias, H. Trace elements in soils and plants. 2.ed. Boca Raton: CRC Press, 1992. 365p.

Kim, C. K.; Lee, S. Reduction of the incidence of rice neck blast by integrated soil improvement practice. Korean Journal of Plant Protection, v.21, p.1518, 1982.
Korndörfer, G. H.; Arantes V. A.; Corrêa, G. F.; Snyder, G. H. Efeito do silicato de cálcio no teor de silício no solo e na produção de grãos de arroz de sequeiro. Revista Brasileira de Ciência do Solo, v.23, n.3, p.623-629, 1999a.

Korndörfer, G. H.; Coelho, N. M.; Snyder, G. H.; Mizutani, C. T. Avaliação de métodos de extração de silício para solos cultivados com arroz de sequeiro. Revista Brasileira de Ciência do Solo, v.23, n.1, p.101-106, 1999b.

Lee, D. B.; Kwon, T. O.; Park, K. H. Influence of nitrogen and silica on the yield and the lodging related traits of paddy rice. Soil and Fertilizers, v.32, n.2, p.15-23, 1990.

Ma, J. F.; Miyake, Y.; Takahashi, E. Silicon as a beneficial element for crop plant. In: Datnoff, L. E.; Korndörfer, G. H.; Snyder, G. (ed.). Silicon in agriculture. New York: Elsevier Science, 2001. p.17-39.

Marschner, H. Mineral nutrition of higher plants. 2.ed. London: Academic Press, 1995. 889p.

Nanda, H. P.; Gangopadhya, Y. Role of silicated cells in rice leaf on brown spot disease incidence by Bipolaris oryzae. International Journal of Tropical Plant Diseases, v.2, p.89-98, 1984.

Notteghem, J. L. Cooperative experiment on horizontal resistance to rice blast. In: International Rice Research Institute (Los Baños, Philippines). Blast and upland rice: report and recommendations from the meeting for international collaboration in upland rice improvement. Los Baños: IRRI, 1981. p.43-51.

Pereira, H. S.; Korndörfer, G. H.; Vidal, A. de A.; Camargo, M. S. de. Silicon sources for rice crop. Scientia Agricola, v.61, n.5, p.522-528, 2004.

Prabhu, A. S.; Barbosa Filho, M. P.; Filippi, M. C.; Datnoff, L. E.; Snyder, G. H. Silicon from rice disease control perspective in Brazil. In: Datnoff, L. E.; Snyder, G. H.; Korndörfer, G. K. Silicon in agriculture. Amsterdam: Elsevier, 2001. v.1, p.293-311.

Prabhu, A. S.; Santos, A. B. dos. Doenças e seu controle. In: Santos, A. B. dos. (ed.). Cultivo da soca de arroz irrigado. Santo Antônio de Goiás: Embrapa Arroz e Feijão, 2004. p.109-126.

Santos, A. B. dos. Importância e características. In: Santos, A. B. dos. (ed.). Cultivo da soca de arroz irrigado. Santo Antônio de Goiás: Embrapa Arroz e Feijão, 2004. p.15-36.

Santos, G. R.; Korndörfer, G. H.; Reis Filho, J. C. D.; Pelúzio, J. M. Adubação com silício: influência sobre as principais doenças e sobre a produtividade do arroz irrigado por inundação. Revista Ceres, v.50, n.287, p.1-8, 2003.

Savant, N. K.; Snyder, G. H.; Datnoff, L. E. Silicon management and sustainable rice production. Advances in Agronomy, v.58, p.151-199, 1997.

Sawant, A. S.; Patil, V. H.; Savant, N. K. Rice hull ash applied to seedbed reduces deadhearths in transplanted rice. International Rice Research Notes, v.19, p.21-22, 1994.

Seebold, K. W.; Datnoff, L. E.; Correa-Victoria, F. J.; Kucharek, T. A.; Snyder, G. H. Effects of silicon and fungicides on the control of leaf and neck blast in upland rice. Plant Disease, v.88, n.3, p.253-258, 2004. 